\title{
Relation between Leafhopper Influxes and Synoptic Weather Conditions
}

\author{
F. A. HuFF \\ Illinois State Water Survey
}

(Manuscript received 14 May 1962, in revised form 30 October 1962)

\begin{abstract}
A study was made of the association of potato leafhopper influxes into Illinois with existing synoptic weather conditions. With data for 25 observed influxes during 1951-59, synoptic weather maps and climatological records were studied to obtain information during and preceding the flights on: wind conditions between the Louisiana source region and Illinois; the presence of fronts in Illinois; the extent and intensity of rainfall in the state; and prevailing temperature conditions.

Results of the study indicated a strong relationship between synoptic weather conditions and leafhopper influxes. Typical meteorological conditions favoring influxes were found to be: a persistent southerly flow of maritime tropical air from the Gulf states into the Midwest for at least 36 hours prior to the Illinois influx; rainshowers or thundershowers on the days of influx; and, the presence of a front, usually a cold front, at the time of the recorded influx.

From the above criteria, days favorable for influxes during 1960 were predicted. Excellent correspondence was obtained between indicated and actual dates of 1960 influxes.
\end{abstract}

\section{Introduction}

The importance of meteorological conditions in the dispersal of insects has been recognized by entomologists for many years and has been discussed in the literature by numerous authors. For example, Uvarov (1931) summarized knowledge on the subject and presented an extensive bibliography. He discussed wind, temperature, pressure, and humidity, and concluded that the daily activities of insects are dependent upon the daily rhythm of the weather. Glick ${ }^{1}$ described the distribution of insects, spiders, and mites in the air, and discussed the influence of various meteorological factors on the distribution. Lawson and others ${ }^{2}$ pointed out the association of wind direction, cold weather, and other weather factors on the dissemination of the beet leafhopper in California. Glick ${ }^{3}$ discussed meteorological conditions in conjunction with the collection of insects by airplane. Wolfenbarger (1959) presented a comprehensive treatment of the dispersal of small organisms in which he discusses the influences of weather factors. An extensive bibliography on the subject is also presented by Wolfenbarger. Space will not permit further

\footnotetext{
${ }^{1}$ Glick, P. A., 1939: The distribution of insects, spiders, and mites in the air. Tech. Bull. No. 673, U. S. Dept. of Agriculture, Washington, D. C.

${ }^{2}$ Lawson, Francis R., Joseph C. Chamberlin and George T. York, 1951: Dissemination of the beet leafhopper in California. Tech. Bull. No. 1030, U. S. Dept. of Agriculture, Washington, D. C.

3 Glick, P. A., 1957: Collecling insects by airplane in Southern Texas. Tech. Bull. No. 1158, U. S. Dept. of Agriculture, Washington, D. C.
}

review of the numerous discussions of weather effects on insect behavior appearing in entomological literature.

In recent years, considerable research has been carried out by the Illinois State Natural History Survey on the migration of the potato leafhopper (Empoasco fabae) into Illinois and the Midwest. These insects attack potatoes, beans, alfalfa, and other crops. Research has shown that heavy spring migrations of leafhoppers from the Mississippi Delta region take place, and that these migrations may be associated with certain meteorological conditions. This finding was lent further support as the result of a detailed case study by Joos ${ }^{4}$ of the weather conditions associated with a strong 1957 influx. Subsequently, discussions between scientists of the Illinois Natural History Survey and the Meteorology Section of the Illinois State Water Survey led to the establishment of a cooperative study to investigate further the association between leafhopper migrations and synoptic weather factors. This study was undertaken to aid the entomologist in verifying observational evidence that leafhoppers migrate from the Mississippi Delta region northward into the Midwest, and in ascertaining the meteorological conditions under which migrations take place and terminate.

Data from 25 Illinois influxes during 1951-1959 were available for analysis in the Natural History Survey files; most of these cases occurred during the 5-year period, 1955-1959. Influx intensity measurements were

\footnotetext{
${ }^{4}$ Joos, L. A., 1957: Trajectory problem. Report on the 1957 potato leafhopper survey, Illinois State Natural History Survey, Urbana, Ill.
} 
made with hand nets, air socks, light traps, and, to a limited extent, with aircraft. The most extensive sampling in Illinois was accomplished by sweeping with hand nets in alfalfa fields by assigned observers. These observers moved throughout the state during spring to obtain representative samples of the insect population. Scientists of the Natural History Survey believe that the observational program was adequate to sample all of the major spring influxes, but not all of the minor migrations. After the major influx which may occur any time after mid-May, it is usually difficult to discern any influxes with a high degree of reliability, because the insect population in the state normally is relatively heavy and spatially variable by that time. Consequently, data used in this study have been restricted to those obtained in April, May, and early June.

\section{Analytical procedure}

It was hypothesized that leafhoppers are mainly advected from the Louisiana source by low-level winds, that they may be washed out of the atmosphere by rain, that temperature may influence them, and that the rapid change in air-mass properties at fronts may affect flight termination. Although, these synoptic factors define only part of the general weather pattern, it was felt that they were sufficient to reflect any significant correlation between leafhopper behavior and existing weather conditions which could be obtained from available data on leafhopper flights.

With data from the 25 cases for 1951-1959, synoptic weather maps and climatological records of the U. S. Weather Bureau were studied to obtain information during and preceding the influxes on: wind conditions in the lower $5000 \mathrm{ft}$ of the atmosphere; the presence of weather fronts in Illinois; the extent and intensity of rainfall associated with the influxes; and the prevailing temperature conditions. Then, based on influx criteria developed in this phase of the study, a list of favorable days for influxes during Spring 1960 was furnished to the Natural History Survey to test the reliability of the relations between leafhopper migrations and synoptic weather obtained from the 1951-1959 data sample.

\section{Results of analyses}

The presence of rainfall in Illinois, usually rainshowers and/or thunderstorms, was the most persistent of the meteorological factors associated with the influx of leafhoppers during the 1951-1959 period. Climatological summaries of the U. S. Weather Bureau ${ }^{5}$ show that rainfall was associated with the increases in insect populations in Illinois in all 25 cases studied. The rainfall was frequently widespread with moderate to heavy daily amounts recorded at numerous stations. Wide-

${ }^{5}$ Climatological data, Illinois, 1951-1960. U. S. Weather Bureau, Washington, D. C. spread rainfall of moderate to heavy intensity was present in 14 out of the 25 cases, or 56 per cent of the time. Daily amounts in excess of one inch were recorded at scattered locations on these days, and, occasionally, daily amounts of two to five inches were recorded. Analysis of rainfall conditions between the Mississippi Delta source region and Illinois indicated little or no precipitation in this area during the 24 hours preceding the Illinois influxes in about $2 / 3$ of the cases. Lack of precipitation minimizes insect washout in fights moving northward from the source region, and appears to be a necessary requirement for heavy midwestern influxes.

In 24 of the 25 cases studied in the 1951-1959 period, synoptic weather fronts were present in Illinois during the influx period, according to U. S. Weather Bureau daily weather maps. Cold fronts, which were most common, were present in 20 of the 25 cases, either alone or in conjunction with other fronts during the influx period. Fronts, of course, are regions of precipitation, temperature changes, and wind shifts, and it may be the presence of these weather events at fronts which is reflected in the strong association between leafhopper influxes and fronts. The distribution of fronts with the leafhopper influxes is shown in Table 1.

Table 1. Fronts vs. leafhopper influxes, 1951-1959.

\begin{tabular}{lcc}
\hline \multicolumn{1}{c}{ Frontal type } & $\begin{array}{c}\text { Number of } \\
\text { influxes }\end{array}$ & $\begin{array}{c}\text { Per cent of all } \\
\text { influxes }\end{array}$ \\
\hline Cold & 12 & 48 \\
Cold plus Warm & 3 & 12 \\
Cold becoming Stationary & 5 & 20 \\
Warm & 3 & 12 \\
Stationary & 1 & 4 \\
None & 1 & 4 \\
\hline
\end{tabular}

In all cases, wind conditions in the lower $5000 \mathrm{ft}$ of the atmosphere were favorable for leafhopper flights from the source region in the Gulf states to Illinois. The general pattern consisted of southeast to southsouthwest winds in the Mississippi Delta region of Louisiana gradually veering to south-southwest to southwest winds in Illinois. Favorable flow conditions were found to exist for at least 36 hours prior to all of the Illinois influxes, sufficient time for flights to reach Illinois from the source region. In the majority of the cases (64 per cent), flow conditions were favorable for 48 hours or longer. Examination of wind speed associated with the 25 Illinois influxes indicated a median speed of 17 knots in the layer from the surface to $5000 \mathrm{ft}$ over the region from the Gulf to Illinois. Individual cases had layer mean winds ranging from 12 to 30 knots. Thus, moderate wind speeds appear to be associated with the migrations normally.

It was found that influxes of leafhoppers into Illinois are usually accompanied by above-normal temperatures, since a persistent flow of air from the southern and southeastern states normally precedes the influxes. 
Average temperatures for the state ranged from slightly above to much above normal during 19 of the 25 influxes, or 76 per cent of the time. Near normal temperatures occurred in five cases, and slightly below normal temperatures in the remaining case. Table 2 shows the relation between temperature departures and influxes in the 25 cases for the entire state and for the northern and southern halves of Illinois. Table 3 shows the mean daily temperature distribution with the 25 cases. In

TABLE 2. Departure from normal mean daily temperature, 1951-1959.

\begin{tabular}{crrr}
\hline $\begin{array}{c}\text { Departure } \\
\left({ }^{\circ} \mathrm{F}\right)\end{array}$ & $\begin{array}{c}\text { Number of cases for given departure } \\
\text { North half }\end{array}$ & $\begin{array}{c}\text { South half } \\
\text { Entire state }\end{array}$ \\
\hline-3 to -5 & 4 & 1 & 1 \\
-2 to +2 & 4 & 6 & 5 \\
+3 to +5 & 4 & 4 & 5 \\
+6 to +10 & 9 & 10 & 10 \\
Over 10 & 4 & 4 & 4 \\
Median & -6 & -6 & -6 \\
\hline
\end{tabular}

TABLE 3. Mean daily temperature distribution, 1951-1959.

\begin{tabular}{cccc}
\hline $\begin{array}{c}\text { Temperature } \\
\left({ }^{\circ} \mathbf{F}\right)\end{array}$ & \multicolumn{2}{c}{$\begin{array}{c}\text { Number of cases for given temperature } \\
\text { North half }\end{array}$} & $\begin{array}{c}\text { South half } \\
\text { Entire state }\end{array}$ \\
\hline $46-50$ & 1 & 0 & 0 \\
$51-55$ & 3 & 1 & 2 \\
$56-60$ & 5 & 2 & 3 \\
$61-65$ & 5 & 4 & 6 \\
$66-70$ & 6 & 8 & 7 \\
$71-75$ & 3 & 8 & 5 \\
$76-80$ & 2 & 2 & 2 \\
& 65 & 69 & 67 \\
\hline
\end{tabular}

20 of the 25 cases, the state mean temperature exceeded $60 \mathrm{~F}$ when the influxes occurred. The median value of the mean daily temperatures ranged from $65 \mathrm{~F}$ in the northern half to $69 \mathrm{~F}$ in the southern part of the state.

\section{Typical influx case}

Typical meteorological conditions associated with a leafhopper influx are illustrated in Figs. 1-3 for the case of 10-12 May 1959, when large increases in population were recorded in Illinois. Fig. 1 shows flow conditions at the $850-\mathrm{mb}$ level (about $5000 \mathrm{ft}$ ) on 9-10 May preceding the increased population. A moderate to strong flow of air off the Gulf of Mexico northward into Illinois is indicated, favorable for migration flights.

Fig. 2 shows the frontal situation during the 10-12 May period. On 10 May, a warm front moved northeastward out of the state. By noon of 11 May, a cold front, oriented east-northeast to west-southwest, had moved into northern Illinois from the north-northwest. This front then slowed down considerably during its passage through Illinois, reaching extreme southern Illinois 24 hours later at noon on 12 May. Movement through Illinois was at an average speed of only $10 \mathrm{mph}$.

Fig. 3 illustrates the rainfall and temperature conditions associated with the 10-12 May influx. Fig. 3a shows the 3-day rainfall totals for the state. Most of the state received over one inch of rainfall and a considerable portion had over two inches. The magnitude of the 3-day storm can be emphasized by reference to the normal May rainfall for the state which ranges from 3.5 inches in the north to 4.5 inches in some portions of the south. Fig. 3b shows the pattern of the departure from normal mean temperature on 10 May at the start of the influx period. Daily mean temperatures are shown

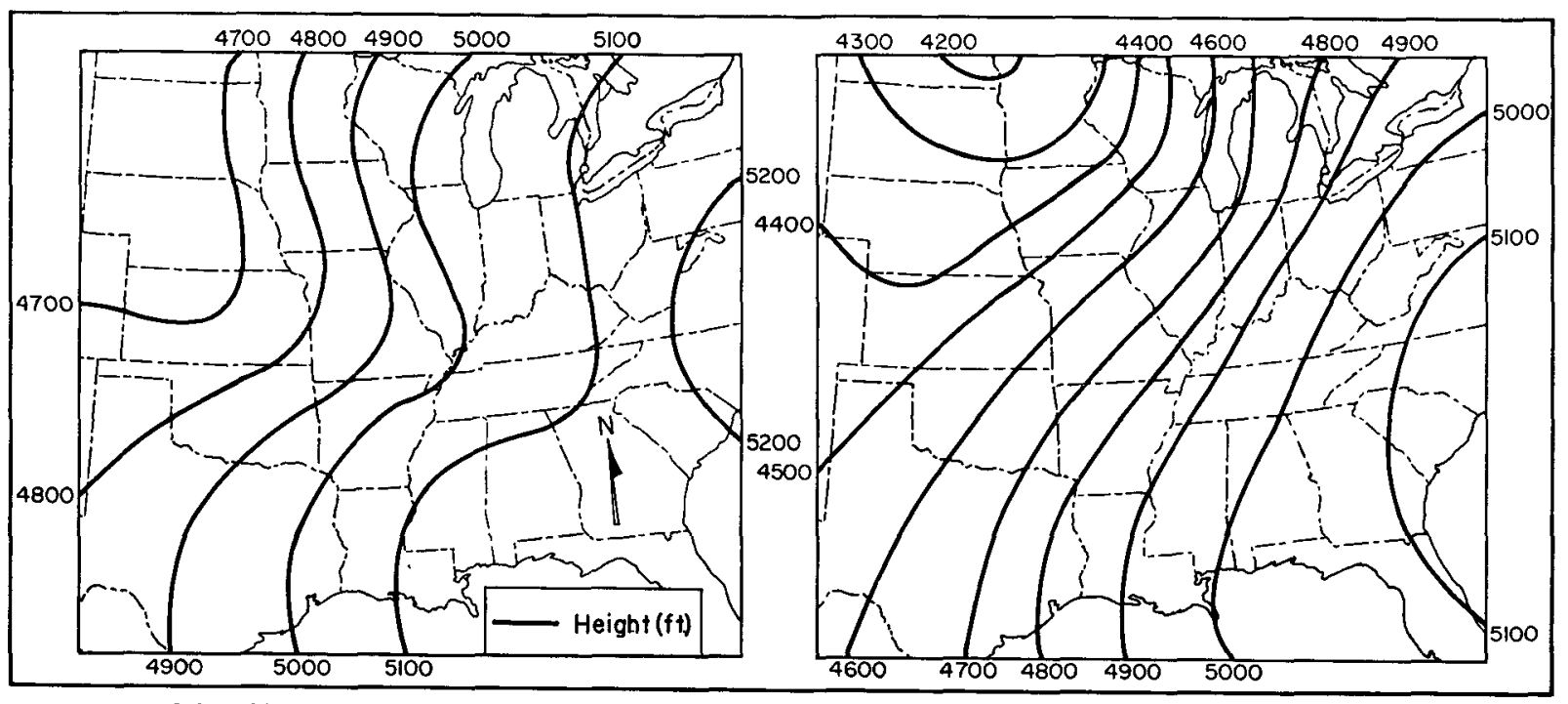

a. 9 MAY 1959, O600 CST

b. 10 MAY 1959,0600 CST

FrG. 1. 850-mb map. 


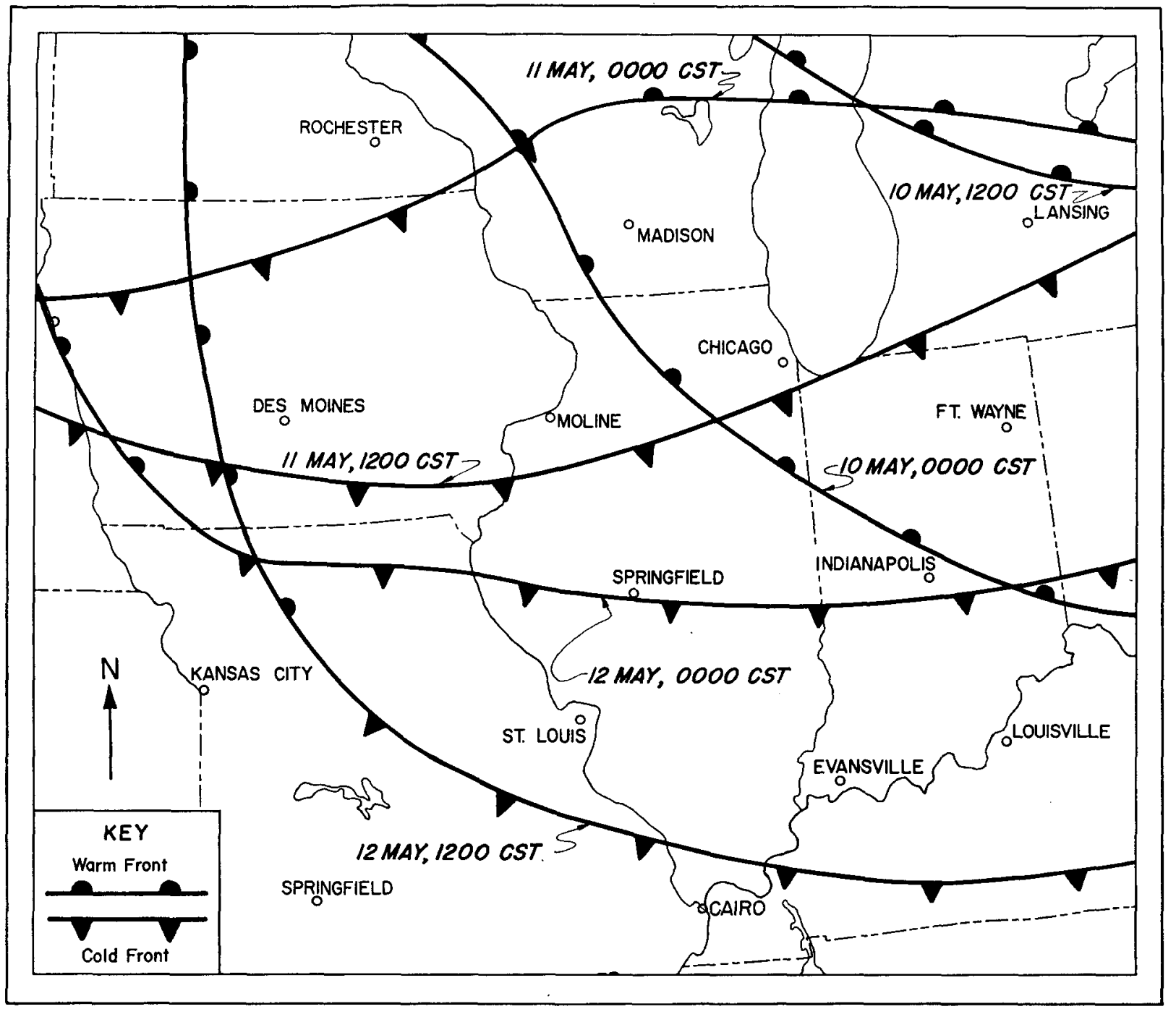

FIG. 2. Frontal pattern on 9 May to 12 May 1959.

also for selected stations. Departures ranged from +6 to $+12 \mathrm{~F}$ over most of the state and daily mean temperatures were near $70 \mathrm{~F}$.

\section{Discussion}

In brief summary, analyses of weather conditions associated with 25 leafhopper influxes into Illinois during 1951-1959 suggest that the migrations are favored by warm southerly winds in the lower atmosphere, and that these flights are terminated upon encounter with stormy weather. Rainfall was found to be the most persistent weather condition associated with the influxes. Possibly the rainfall itself or turbulence associated with rainstorms forces the insects to the ground, either by washout or downdrafts. Fronts, present during all except one influx, tend to increase both the extent and intensity of rainfall and the degree of atmospheric turbulence. The decrease in temperature across fronts in the path of northward-moving flights and the cooler temperatures which usually occur with the passage of rainshowers and thunderstorms could be factors also in flight termination. However, based on the study of the 25 cases, the most important factors in termination of flights are encounter with fronts and rainfall; warm, southerly winds are the most important factor in the initiation and sustentation of flights.

\section{1960 test of relationships}

In a test of the validity of the relationships between leafhopper influxes and meteorological conditions developed from 1951-1959 data, a list of seven days favorable for influxes in Spring 1960, based upon study 


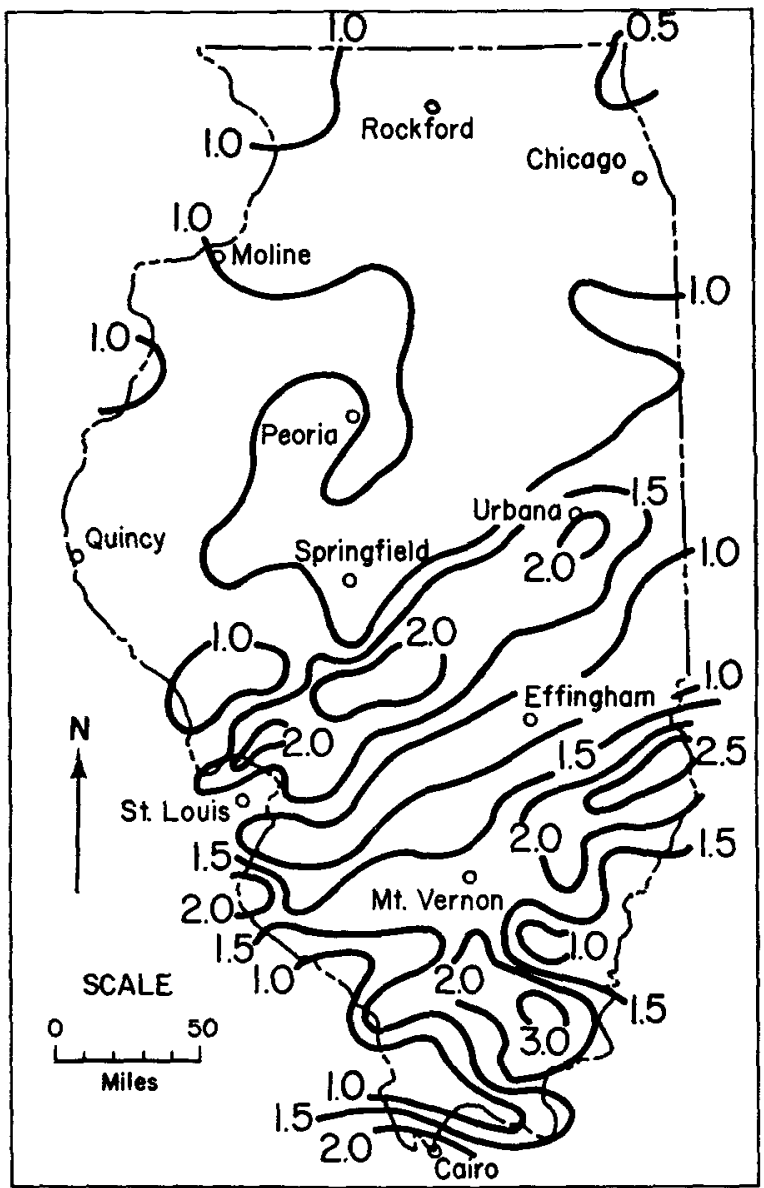

a. TOTAL RAINFALL FOR 10-12 MAY

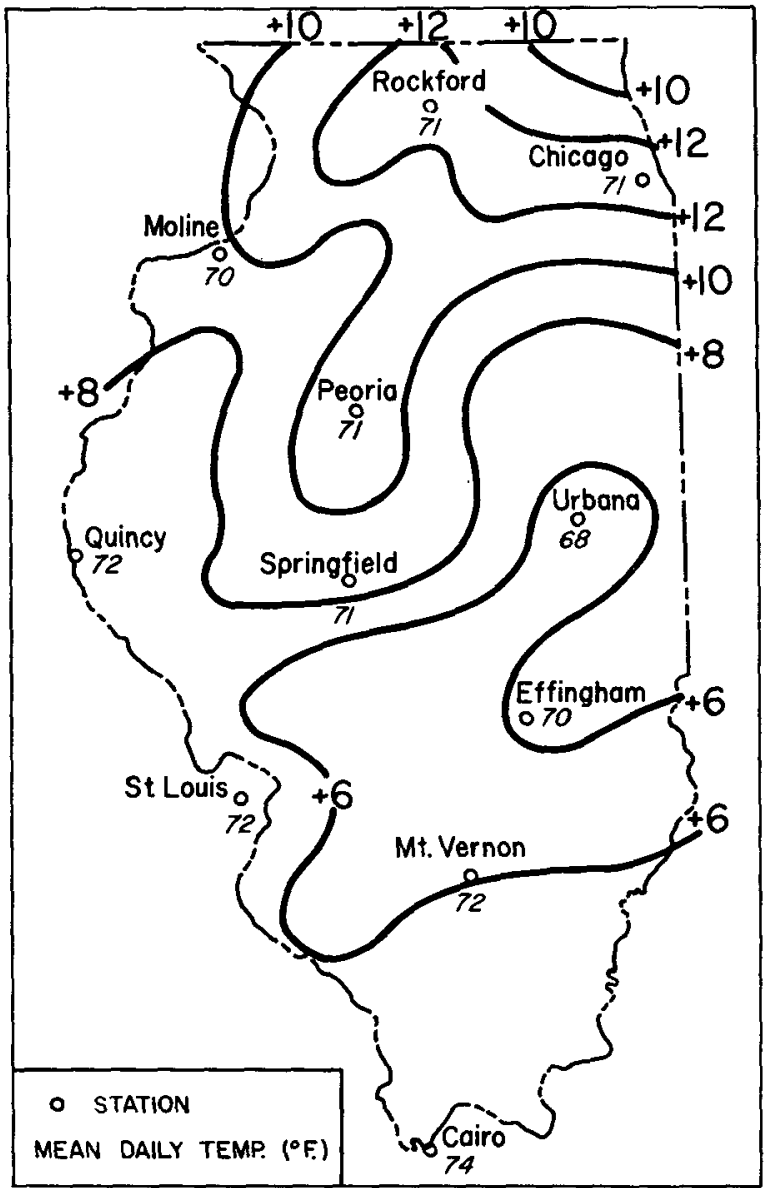

b. DEPARTURE FROM NORMAL MEAN TEMPERATURE ( $\left.{ }^{\circ} \mathrm{F}\right)$ ON 10 MAY 1959

FIG. 3. Rainfall and temperature distribution.

of meteorological data, was furnished the Natural History Survey. Excellent correspondence was obtained between indicated and actual dates of the influxes recorded. On six of the seven indicated dates increases in leafhopper activity were noted. In the one negative case, Natural History Survey entomologists indicated that leafhopper populations in the source area were very low at the time and a small influx not detected by their sampling program may have occurred.

\section{Conclusions}

An excellent relationship was established between meteorological conditions and leafhopper influxes into the Midwest from the Mississippi Delta region. This study provides an excellent example of the application of meteorology to scientific research in other fields.

Acknowledgments. The author is indebted to Dr. George Decker, Head, Section of Economic Entomology, Illinois State Natural Survey, who suggested this study, furnished the necessary data on leafhopper influxes, and provided valuable suggestions and comments during accomplishment of the study.

\section{REFERENCES}

Uvarov, B. P., 1931: Weather, climate, and insects. Transactions of the Entomological Society of London, 79, 87-136.

Wolfenbarger, D. O., 1959: Dispersion of small organisms. Lloydia, A Quarterly Journal of the Biological Sciences, 22, 1-106. 